\title{
Comparison of multi-drug resistant environmental methicillin-resistant Staphylococcus aureus isolated from recreational beaches and high touch surfaces in built environments
}

\author{
Marilyn C. Roberts ${ }^{1}{ }^{*}$, Olusegun O. Soge ${ }^{2}$ and David $\mathbf{N o}^{1}$ \\ 1 Department of Environmental and Occupational Health Sciences, University of Washington, Seattle, WA, USA \\ ${ }^{2}$ Department of Global Health, University of Washington, Seattle, WA, USA
}

\author{
Edited by: \\ Marcelo Tolmasky, California State \\ University Fullerton, USA \\ Reviewed by: \\ David Dryden, University of \\ Edinburgh, UK \\ Charles W. Knapp, University of \\ Strathclyde, UK \\ *Correspondence: \\ Marilyn C. Roberts, Department of \\ Environmental and Occupational \\ Health Sciences, School of Public \\ Health, University of Washington, Box \\ 357234, Seattle, WA 98195-7234, \\ USA. \\ e-mail: marilynr@u.washington.edu
}

Over the last decade community-acquired methicillin-resistant Staphylococcus aureus (MRSA) has emerged as a major cause of disease in the general population with no health care exposure or known classical risk factors for MRSA infections. The potential community reservoirs have not been well defined though certain strains such as ST398 and USA300 have been well studied in some settings. MRSA has been isolated from recreational beaches, high-touch surfaces in homes, universities, and other community environmental surfaces. However, in most cases the strains were not characterized to determine if they are related to community-acquired or hospital-acquired clinical strains. We compared 55 environmental MRSA from 805 samples including sand, fresh, and marine water samples from local marine and fresh water recreational beaches $(n=296)$, high touch surfaces on the University of Washington campus $(n=294)$, surfaces in UW undergraduate housing $(n=85)$, and the local community $(n=130)$. Eleven USA300, representing $20 \%$ of the isolates, were found on the UW campus surfaces, student housing surfaces, and on the community surfaces but not in the recreational beach samples from the Northwest USA. Similarly, the predominant animal ST133 was found in the recreational beach samples but not in the high touch surface samples. All USA300 isolates were multi-drug resistant carrying two to six different antibiotic resistance genes coding for kanamycin, macrolides and/or macrolides-lincosamides-streptogramin B, and tetracycline, with the majority (72\%) carrying four to six different antibiotic resistance genes. A surprising $98 \%$ of the $55 \mathrm{MRSA}$ isolates were resistant to other classes of antibiotics and most likely represent reservoirs for these genes in the environment.

Keywords: MRSA, environmental, recreational beaches, high touch surfaces, USA300

\section{INTRODUCTION}

Staphylococcus aureus is part of the normal flora and can be found in the anterior nares as well as on the skin, axilla, perineum, and pharynx. It has been estimated that $25-35 \%$ of healthy humans in the general community have $S$. aureus in their anterior nares (Grundmann et al., 2006). However the range varies depending on the population examined and when the study was done. It is now thought that $\sim 20 \%$ of population almost always carries $S$. aureus, another $20 \%$ rarely carries S. aureus, and the remaining $60 \%$ of the population is intermittently colonized (Kluytmans et al., 1997).

Methicillin-resistant $S$. aureus (MRSA) was first identified over 50 years ago and has become a major nosocomial and community pathogen. MRSA strains are $S$. aureus that have a mecA gene which codes for a unique penicillin-binding protein that has decreased affinity for $\beta$-lactams. This protein allows for cell growth in the presence of penicillins and other $\beta$-lactam antibiotics, which are the antibiotics of choice for staphylococcal skin and soft tissue infections (Eady and Cove, 2003; Grundmann et al., 2006). Over the last decade community-acquired MRSA (CA-MRSA) causing primarily skin and soft tissue infections has emerged as a major cause of disease in the general population with no health care exposure or known classical risk factors for MRSA infections around the world (King et al., 2006). In 2005 there were $~ 19,000$ deaths due to MRSA in hospitalized USA patients. More importantly three fourth of the US MRSA infections were in people that had not been previously hospitalized, had no contact with hospitals, and were part of the general community (Klevens et al., 2007). CA-MRSA morbidity and mortality per 100,000 people have been estimated at 4.6 and 0.5 , respectively (Klevens et al., 2007). CA-MRSA strains initially from community patients are now entering the hospital environments to become the predominant nosocomial MRSA isolates (Popovich et al., 2008). In North America, most CA-MRSA disease is due to a single strain, USA300, which produces a number of toxins and has the ability to cause skin and soft tissue infections in otherwise healthy individuals and appears to be more robust on fomites (Desai et al., 2011). In other geographical locations, CAMRSA can be a variety of different strains (Nimmo and Coombs, 2008; Bartels et al., 2009). Originally CA-MRSA causing disease 
was less likely to be resistant to other antimicrobial agents than MRSA strains isolated from the high-antibiotic selection pressure of the hospital environment (Eady and Cove, 2003).

Staphylococcus aureus and MRSA can be transmitted from people-to-people, from fomites-to-people, and from air-to-people (Huang et al., 2006; Zuckerman et al., 2009). People colonized or infected with $S$. aureus or MRSA shed into their environments contaminating surfaces and fomites at concentrations sufficient for survival for extended periods of time in the environment which should allow for transfer to skin, clothing, and other fomites (Boyce et al., 1997; Otter et al., 2011).

Environmental reservoirs associated with healthcare settings and closed communities such as daycares, schools, prisons, and sport teams have been examined (Centers for Disease Control and Prevention, 2001; Eady and Cove, 2003; Nguyen et al., 2005; Roberts et al., 2011a,b,c). S. aureus and MRSA contamination in the marine environment have been examined including shedding from recreational bathers, untreated wastewater, and urban runoff (Selvakumar and Borst, 2006; Elmir et al., 2007; Börjesson et al., 2009; Plano et al., 2011). Over the past several years, S. aureus and MRSA have been isolated from marine water, stream water, and intertidal sand samples from beaches in California (Goodwin and Pobuda, 2009), Florida (Abdelzaher et al., 2010), Hawaii (Tice et al., 2010; Viau et al., 2011), and the Pacific Northwest (Soge et al., 2009). MRSA spatial distribution or strain characterization was not addressed in the studies by Goodwin and Pobuda (2009) in California and Tice et al. (2010) in Hawaii. A more recent study sampled fresh water streams draining into coastal beaches on O'ahu Hawaii found S. aureus (Viau et al., 2011). Temporal and spatial distribution of pathogenic microorganisms including S. aureus was examined in a Florida study (Abdelzaher et al., 2010), however none of the presumptive $S$. aureus isolates were biochemically confirmed as S. aureus. The study by Soge et al. (2009) identified MRSA and/or S. aureus isolated in 2008, from 6 of 10 marine beaches from the Pacific Northwest, however the number of samples taken was limited. That study found that the MRSA isolates were related to strains previously associated with hospitalacquired MRSA (five SSCmec type I, and one non-typeable and ST types $30,45,59,1405)$, and the S. aureus isolates (ST15, ST30, ST59) suggested that they are related to hospital-acquired MRSA. ST5, ST30, ST45, ST59 were all major clonal complexes found in the United States (Schwalm et al., 2011).

In this current paper we compare 55 environmental MRSA isolates, including 11 USA300, collected from 805 samples taken from fresh and marine beaches, high touch surfaces within the community and the University of Washington. This represents the first comparison of characterized MRSA isolates from different natural and built environments.

\section{MATERIALS AND METHODS BACTERIAL ISOLATES}

All samples from recreational marine or fresh water beaches, and swabs from the environmental surfaces were enriched in Bacto ${ }^{\circledR} \mathrm{m}$ Staphylococcus broth $(1.5 \times)$ (Difco Laboratories, Sparks, MD, USA) supplemented with a final concentration of $75 \mu \mathrm{g} / \mathrm{L}$ polymyxin B and $0.1 \%$ potassium tellurite (Sigma Co., St. Louis, $\mathrm{MO}, \mathrm{USA}$ ) and $50 \mathrm{ml}$ of media was used for wash clothes used for sampling the washing machines as previously described (Roberts et al., 2011c; Levin-Edens et al., 2012). All samples were incubated in $5 \% \mathrm{CO}_{2}$ at $36.5^{\circ} \mathrm{C}$ until turbid and black. Positive samples were diluted and plated onto Bacto ${ }^{\circledR}$ Staphylococcus Medium 110 (Difco) supplemented with $10 \mu \mathrm{g} / \mathrm{ml}$ methicillin and $0.01 \%$ potassium tellurite and Bacto ${ }^{\circledR}$ Mannitol Salts Agar (Difco), and the resulting strains were biochemically verified as $S$. aureus and confirmed as mecA positive by PCR assay as previously described (Roberts et al., 2011c; Levin-Edens et al., 2012). Twenty-two MRSA isolated from fresh water draining into recreational marine or fresh water beaches, seven MRSA isolates collected from sand, and two MRSA isolates collected from marine water identified from sand, fresh, and marine water samples from local marine and fresh water recreational beaches $(n=296)$ in 2010 (Levin-Edens et al., 2012) were included in the study. An additional 24 MRSA isolates from frequently touched 509 non-hospital environmental surfaces taken at a large university $(n=294)$, student homes $(n=85)$, and local community sites $(n=130)$ collected 2009-2010 (Roberts et al., 2011c) were included in the comparison (Table $\mathbf{1}$ ).

\section{CHARACTERIZATION OF MRSA STRAINS}

The SCCmec typing was done by multiplex PCR assay for types I-V using positive controls. SCCmec typing classifies the SCCmec elements based on their structural differences and has been used to discriminate MRSA strains and define MRSA clones ${ }^{1}$. Those that were not SCCmec type I-V were labeled as non-typeable (NT) (Soge et al., 2009). The MLST was previously determined by PCR and sequencing of the PCR products for the seven housekeeping genes (Soge et al., 2009). Alleles were assigned by a comparison of their sequences with the corresponding loci in the S. aureus MLST database and combined into an allelic profile with unique sequence type $(\mathrm{ST})^{2}$. Drug resistance genes including kanamycin resistance gene, aadD, macrolide-lincosamide-streptogramin $\mathrm{B}$ resistance genes $\operatorname{erm}(\mathrm{A}), \operatorname{erm}(\mathrm{B}), \operatorname{erm}(\mathrm{C})$, and macrolide-streptogramin $\mathrm{B}$ resistant $m s r(\mathrm{~A})$ gene, and tetracycline resistance genes tet $(\mathrm{M})$ and tet $(\mathrm{K})$ were previously determined by PCR assays (Soge et al., 2009). These specific antibiotic resistance genes were selected because they have previously been identified in MRSA isolates or have been associated with SCCmec elements (Soge et al., 2009; McDougal et al., 2010; Roberts et al., 2011a,b,c; Levin-Edens et al., 2012). Pulsed-field gel electrophoresis (PFGE) analysis was previously done and isolates were compared to four clinical MRSA USA300 strains used as positive controls to determine whether the environmental isolates were related to USA300 clone (McDougal et al., 2010).

\section{RESULTS AND DISCUSSION DISTRIBUTION OF MRSA ISOLATES}

Methicillin-resistant Staphylococcus aureus was isolated from $10 / 85(11.8 \%)$ university student homes surfaces and five $(63 \%)$ of the eight undergraduate student homes had MRSA positive samples. The percentage of MRSA positive samples, which include only samples that yielded MRSA isolates and was a portion of the

\footnotetext{
${ }^{1}$ http://www.staphylococcus.net/

${ }^{2}$ http://saureus.mlst.net/
} 
samples which were contaminated with $S$. aureus, in our university study was 10 -fold higher than the $1.1 \%$ MRSA positive found from 1,320 surface samples taken from 35 homes in the Boston area (Scott et al., 2009). Our study had higher number of MRSA positive homes compared to the $9 / 35(25.7 \%)$ of the homes that were contaminated with MRSA in the Boston study. In the university study, eight (9.4\%) methicillin-susceptible S. aureus (MSSA) isolates from $3(37.5 \%)$ homes versus the Boston study which found MSSA contaminated surfaces in 34 (97.1\%) of 35 Boston homes. However, the demographics of the household members did vary between the current and previous study as did the number of samples per home and the number of homes tested (Scott et al., 2009). Thirty-one (10.5\%) of the 296 recreational beach samples were positive for MRSA with 22 isolates (71\%) coming from fresh water streams running into the marine and freshwater beaches. Fourteen $(4.7 \%)$ of the recreational beach samples were $S$. aureus positive with $12(85.7 \%)$ of the isolates coming from the fresh water stream samples draining into the marine beaches. A recent study in Hawaii found S. aureus in $19(86.4 \%)$ of 22 fresh water streams with $42(48.8 \%)$ of the 86 samples positive for $S$. aureus and one (5.2\%) sample positive for MRSA (Viau et al., 2011). The source of the isolates was not identified nor was potential environmental sources examined or isolates further characterized in the Viau et al. (2011) study. Ten (3.4\%) out of 294 university surface samples were MRSA positive, while nine (3.1\%) were MSSA. This compares to an earlier study which found no MRSA from 70 high touch surfaces in a large urban US university, though samples from keyboards, telephone mouthpieces, and an elevator button were positive for S. aureus (Brooke et al., 2009). Four (3.1\%) out of 130 community samples were MRSA positive, and one $(0.8 \%)$ sample was MSSA positive. The closest community studies for comparison have been from public transport system. A London study found $9(8 \%)$ of the 112 samples taken from hand-touch surfaces in the public transport system and in public areas of a hospital were positive for $S$. aureus but no MRSA was isolated (Otter and French, 2009). A recent study from Japan where environmental samples were collected from 2008 to 2010 found 8 (2.3\%) of the 349 trains examined were positive for MRSA (Iwao et al., 2012).

Eleven $(20 \%)$ of the 55 isolates had PFGE patterns that indicated that they were USA300 strains, the most prevalent community-acquired MRSA in the United States (Tenover and Goering, 2009). However in other parts of the world other strains of CA-MRSA have been identified (Nimmo and Coombs, 2008; Bartels et al., 2009). The USA300 isolates were not evenly distributed in all the environments sampled since all 11 came from samples in built environmental high touch surfaces (student housing 6/10; university 4/10; and community $1 / 4$ ). Three different MLST types were associated with the USA300 PFGE pattern including ST5, ST8, and ST30 (Table 1).

\section{DRUG RESISTANCE CHARACTERIZATION}

Originally, CA-MRSA isolates were less likely to be resistant to other classes of antibiotics, however over the last decade USA300 isolates have become increasingly resistant to fluoroquinolones with 54\% resistant by 2006 (Eady and Cove, 2003; McDougal et al., 2010). An early collection of 187 MRSA strains identified 30 USA300 isolates that were multiple-drug resistant and carried macrolide [ $m s r(\mathrm{~A})$ gene], and/or macrolide, lincosamide-streptogramin B $[\operatorname{erm}(\mathrm{A}) \operatorname{erm}(\mathrm{C})$ genes], and/or tetracycline resistance gene $[$ tet $(\mathrm{K})]$, and/or levofloxacin resistance due to gyrase mutations (Tenover et al., 2006). While a more recent study of 823 USA300 clinical isolates from the Centers for Disease Control and Prevention (CDC) collection found that $43 \%$ of the isolates were resistant to erythromycin and carried the msr(A) gene and $43 \%$ were resistant to erythromycin due to the presence of the $m s r(\mathrm{~A})$ gene plus levofloxacin resistance due to gyrase mutations, and $8.4 \%$ were resistant to tetracycline due to presence of the tet $(\mathrm{K})$ gene of which some also carried the msr(A) gene and/or the gyrase mutations, leaving just 5.6\% susceptible to other classes of antibiotics examined (McDougal et al., 2010). However few groups have characterized the antibiotic resistance patterns of MRSA isolates found in the environment besides the study of Soge et al. (2009). In that study, five MRSA SCCmec type I isolates were resistant to one to four classes of antibiotics and all five carried the erm(A) gene, one carried both tet $(\mathrm{K})$ and tet $(\mathrm{M})$ genes, and one carried the tet $(\mathrm{K})$ and the other carried the tet $(\mathrm{M})$ tetracycline resistance genes. One of the MRSA isolates was able to transfer the $\operatorname{tet}(\mathrm{M})$ and $\operatorname{erm}(\mathrm{A})$ genes in mating experiment suggesting that MRSA strains could be environmental reservoirs for antibiotic resistance genes. In addition, 17/21 (81\%) of the methicillin-resistant coagulase negative Staphylococcus spp. (MRCoNS) were resistant to one to five other classes of antibiotics and carried combinations of $\operatorname{erm}(\mathrm{B}), \operatorname{erm}(\mathrm{C}), \operatorname{msr}(\mathrm{A}), \operatorname{tet}(\mathrm{K})$, and/or tet $(\mathrm{M})$ genes suggesting that MRCoNS strains could also be environmental reservoirs for mobile antibiotic resistance genes. In contrast, none of the environmental MSSA isolates carried any of the resistance genes examined.

Fifty-two (95\%) isolates in the current study carried a variety of other antibiotic resistance genes and were multi-drug resistant, including all 11 USA300 isolates. Only three (5.5\%) of the 55 MRSA isolates were negative by PCR for all seven antibiotic resistance genes examined and represented three different MLST types (Table 1). The most commonly found gene aadD was identified in $45(82 \%)$ isolates, $42(76 \%)$ isolates were positive for $m s r(\mathrm{~A}), 46(84 \%)$ isolates positive for either tet $(\mathrm{K})$ and/or tet $(\mathrm{M})$, 27 (49\%) isolates positive for $\mathrm{erm}(\mathrm{C})$, and 7 (13\%) isolates positive for erm(A). None of the MRSA isolates carried the erm(B) gene. Iwao et al. (2012) examined susceptibilities of eight MRSA isolates from the public trains to nine other non- $\beta$-lactam antimicrobial agents and all were resistant to two to seven of the agents tested though specific resistance genes present were not determined. Seven $(87.5 \%)$ of the eight strains resistant to kanamycin likely carried the aadD gene, which is similar to the $82 \%$ found in the current study, while $4(50 \%)$ were macrolide resistant and $3(37.5 \%)$ were clindamycin resistant. Three $(75 \%)$ of the four Japanese isolates identified as ST8 CA-MRSA were resistant to gentamicin and kanamycin.

Nineteen (35\%) of the MRSA isolates were positive for one to three different antibiotic resistance genes, and included 8 (57\%) of the 13 MLST types from all the different environments and five of the USA300 strains. While $33(60 \%)$ of the MRSA isolates carried four to six of the genes analyzed and included isolates from all the different environments with all the 13 MLST types and 6 of the 11 USA300 included in this group (Table 1). 
Table 1 | Genotypic characteristics of MRSA isolates from recreational beaches and built environmental high touch surfaces.

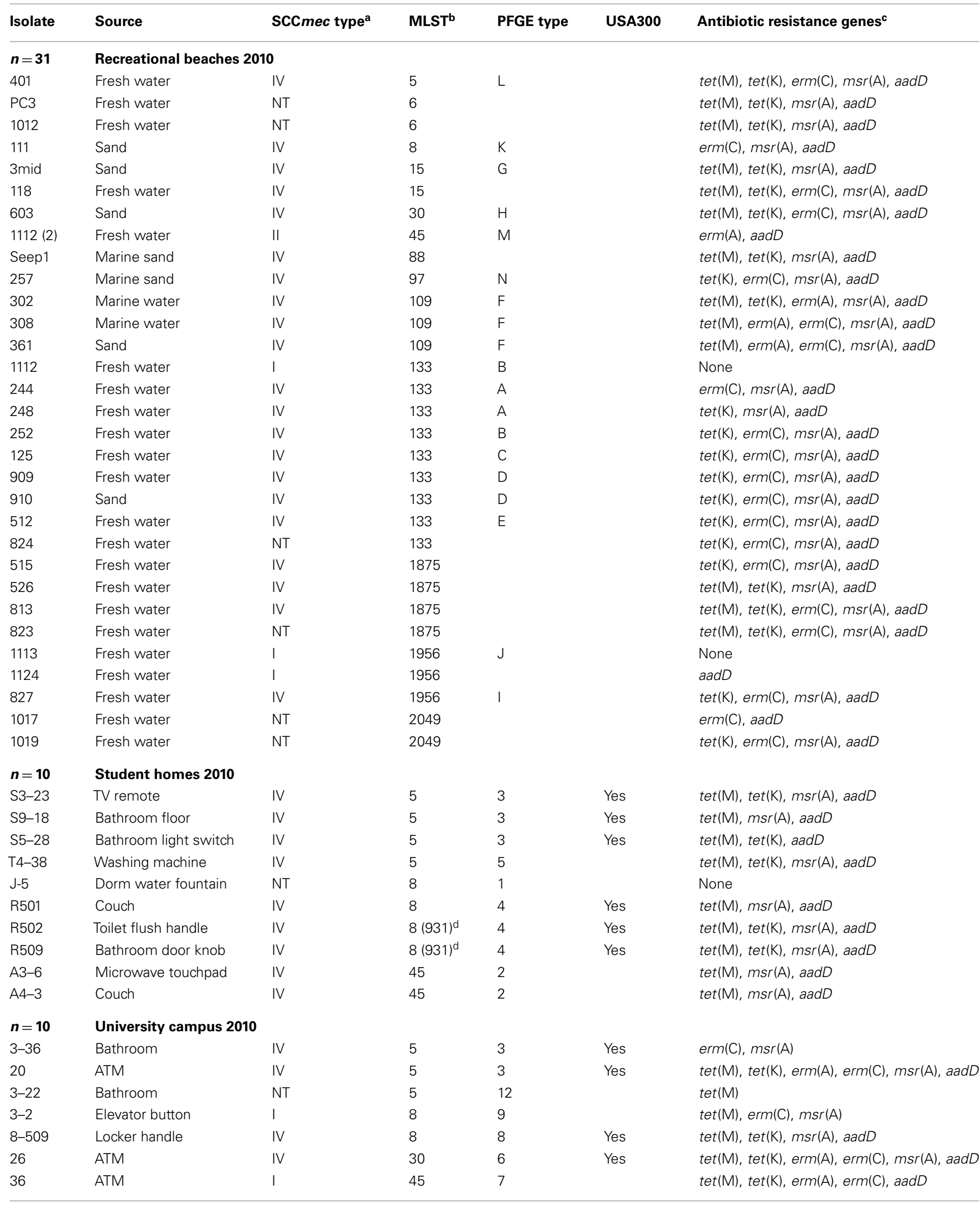


Table 1 | Continued

\begin{tabular}{|c|c|c|c|c|c|c|}
\hline Isolate & Source & SCCmec type ${ }^{a}$ & MLST $^{\mathbf{b}}$ & PFGE type & USA300 & Antibiotic resistance genes ${ }^{c}$ \\
\hline $3-6$ & Bathroom floor & NT & 97 & 11 & & tet $(\mathrm{M})$ \\
\hline $3-8$ & Elevator button & NT & 97 & 10 & & tet $(\mathrm{M})$ \\
\hline $3-10$ & Study lounge floor & NT & 97 & 10 & & $\operatorname{tet}(\mathrm{M}), \operatorname{erm}(\mathrm{C})$ \\
\hline$n=4$ & Community 2009-2010 & & & & & \\
\hline 40 & ATM & NT & 5 & 3 & Yes & $\operatorname{tet}(\mathrm{M}), \operatorname{msr}(\mathrm{A})$ \\
\hline 55 & ATM & IV & 8 & 13 & & $\operatorname{tet}(\mathrm{M}), \operatorname{erm}(\mathrm{C}), \operatorname{msr}(\mathrm{A})$, aadD \\
\hline $5-3$ & Library computer touch screen & NT & 30 & 14 & & $\operatorname{tet}(\mathrm{K})$, aadD \\
\hline $5-4$ & Library computer touch screen & IV & 30 & 14 & & tet $(\mathrm{M})$, tet $(\mathrm{K}), \operatorname{msr}(\mathrm{A})$, aadD \\
\hline
\end{tabular}

${ }^{a}$ SCCmec I-V was tested. If not one of these types, listed as non-typeable (NT); ${ }^{b} M L S T$ typing using seven housekeeping genes; ${ }^{c}$ Kanamycin resistance gene, aadD; macrolide, lincosamide-streptogramin B resistance genes erm (A), erm(B), erm (C), and msr(A) gene and tetracycline resistance genes tet(M) and tet(K) were tested; 'ST931 has recently been reassigned as ST8 due to revision of the gmk locus (Larsen et al., 2012).

Twenty-two (40\%) isolates carried four different antibiotic resistance genes and were isolated from the recreational beaches $(n=15)$, student homes $(n=4)$, university sites $(n=1)$, and community sites $(n=2)$. Ten of the isolates carried $\operatorname{aadD}, \operatorname{erm}(\mathrm{C})$, $m s r(\mathrm{~A})$, and $t e t(\mathrm{~K})$ genes and included ST97 $(n=1)$, ST133 $(n=6)$, ST1875 $(n=1)$, ST1956 $(n=1)$, and ST2049 $(n=1)$, and eight were SCCmec IV and two NT. Eleven isolates carried aadD, $m s r(\mathrm{~A})$, tet $(\mathrm{K})$, and tet $(\mathrm{M})$ genes and included ST5 $(n=2)$, ST6 $(n=2)$, ST8 $(n=3)$, ST15 $(n=1)$, ST30 $(n=1)$, ST88 $(n=1)$, and ST1875 $(n=1)$. Four $(36 \%)$ of the 11 MRSA were USA300 strains by PFGE analysis.

The highest number of resistance genes was found in two USA300 isolates, from the University of Washington sites. They were positive for 6 genes [aadD, $\operatorname{erm}(\mathrm{A}), \operatorname{erm}(\mathrm{C}), \operatorname{msr}(\mathrm{A}), \operatorname{tet}(\mathrm{K})$, and tet $(\mathrm{M})$ ], included ST5 and ST30, and both isolates carried the SCCmec IV element. Nine (16\%) isolates which carried five different antibiotic resistance genes were isolated from the recreational beaches $n=8$, and university sites $n=1$. Five isolates were positive for $\operatorname{aadD}, \operatorname{erm}(\mathrm{C}), m s r(\mathrm{~A}), \operatorname{tet}(\mathrm{K})$, and $\operatorname{tet}(\mathrm{M})$ genes, included $\operatorname{ST5}(n=1), \operatorname{ST} 15(n=1), \operatorname{ST} 30(n=1), \operatorname{ST} 1875(n=2)$, and four of the five isolates carried the SCCmec IV element. Two SCCmec IV, ST109 MRSA isolates from the recreational beaches were positive for $\operatorname{aadD}, \operatorname{erm}(\mathrm{A}), \operatorname{erm}(\mathrm{C}), m s r(\mathrm{~A})$, and tet( $\mathrm{M})$ genes. One other SCCmec IV, ST109 isolate from the beach was positive for $\operatorname{aadD}, \operatorname{erm}(\mathrm{A}), m s r(\mathrm{~A}), \operatorname{tet}(\mathrm{K})$, and tet $(\mathrm{M})$ genes (Table 1$)$. One SCCmec I, ST45 isolate from the university site was positive for $\operatorname{aadD}, \operatorname{erm}(\mathrm{A}), \operatorname{erm}(\mathrm{C}), \operatorname{tet}(\mathrm{K})$, and $\operatorname{tet}(\mathrm{M})$ genes (Table $\mathbf{1})$.

\section{COMPARISON OF SCCmec TYPING AND MLST OF ISOLATES ACROSS DIFFERENT WA ENVIRONMENTS}

Of the 55 MRSA isolates, 35 (63.6\%) carried the SCCmec IV, while $14(25.5 \%)$ were non-typeable which meant they did not carry SCCmec I-V, five $(9.1 \%)$ carried the SCCmec I and one (1.8\%) carried the SCCmec II (Table 1). In the much smaller Japanese study (Iwao et al., 2012), the SCCmec IV was also the most common $[4 / 8(50 \%)]$ with three (37.5\%) isolates carrying the SCCmec II and one (12.5\%) the SCCmec I elements. Few other studies of environmental MRSA have SCCmec typed their isolates.

There were 13 different MLST types identified from the WA isolates. Nine (69\%) of these MLST types have commonly been isolated from humans (see text footnote 2). All 13 of the MLST types were found in MRSA isolated from the WA recreational beaches, five MLST types were found in MRSA isolated from the university, three MLST types (ST5, ST8, and ST45) were found in MRSA isolated from student home surfaces, and three MLST types (ST5, ST8, and ST30) were found in MRSA from the community surfaces. Two new MLST types ST1875 $(n=4)$, three SCCmec IV and one NT, and ST2049 $(n=2)$ both NT, were identified in recreational beach samples. The ST2049 is closely related to ST1962 which has previously been identified in squirrels as has ST1956 (see text footnote 2), both of which were found in the recreational beach samples. Interestingly, two of the three ST1956 isolates carried SCCmec I, more commonly associated with hospital-acquired MRSA. ST1875 (SCCmec IV, $n=3$; NT, $n=1$ ) is closely related to recently identified human ST1176 (CC5) from Brazil (Carmo et al., 2011) and a hospital-acquired ST1176 MRSA strain 2929B reported from Boston, MA, USA and thus could be of human origin (see text footnote 2).

Twenty-six (47\%) of the MRSA belonged to three of the 13 MLST types and included nine isolates of ST133 (CC133), nine isolates of ST5 (CC5), and eight isolates of ST8 (CC8). ST5 and ST8 were found in all four environments (Table 1). All nine ST133 isolates were from both the marine and fresh recreational beaches and surrounding fresh water streams draining into the recreational beaches at multiple time points (Levin-Edens et al., 2012). Based on difference in PFGE patterns the nine isolates represented at least five different strains (Table 1). Seven of the MRSA strains representing all five different PFGE patterns carried the SCCmec IV element, one carried SCCmec I element, and one carried an element that was different than the I-V. Smyth et al. (2009) stated that S. aureus ST133 is an ungulate-animal-specific genotype with no association with humans reported in the literature. The ST133 was the most common lineage reported in S. aureus isolates collected from Danish small ruminants (65\% of 179 sheep and 55\% of 17 goats) (Eriksson et al., 2013). ST133 has been isolated from German wild boars (Meemken et al., 2013), and Japanese cats and dogs (Sasaki et al., 2012). More recently a single MRSA ST133 has been identified from 66 MRSA isolates with seven major clonal complexes from nasal swabs collected from patients upon admission to intensive care units at Pennsylvania State University (Schwalm 
et al., 2011). Thus it is likely that MRSA ST133 is only rarely associated with humans, which correlates with its absence from human built environment surfaces. It is possible that ST133 is associated with common wild and/or pet animals found in urban areas such as Seattle in addition to ungulates and thus explains the wide distribution among the recreational beach areas at multiple time points within the city but its absence from surfaces in built environments in the same geographical area.

The nine ST5 isolates were found at the beaches $(n=1)$, and on the high touch surfaces in the student homes $(n=4)$, university campus $(n=3)$, and community sites $(n=1)$ (Table 1$)$, represented four different PFGE patterns, seven were SCCmec IV and two were NT. ST5 has been associated with humans, chickens, turkey, and pork (see text footnote 2). USA100 a common hospital MRSA is ST5 and is part of the major clonal complex which is widely distributed (Schwalm et al., 2011; Iwao et al., 2012; Verghese et al., 2012; Kawaguchiya et al., 2013). ST5 was found in all four WA environments studied (Table 1).

There were eight ST8 isolates and like ST5 found in all environments sampled (recreational $n=1$; students homes $n=4$; university $n=2$; community $n=1$ ). Six of the ST 8 were SCCmec IV isolated at the beaches, student homes, university campus, and community, while ST8 SCCmec I was isolated on a university surface and the ST8 NT isolated from student dorm. ST8 has been associated with USA300 clonal type which is now being found in hospital setting (Kawaguchiya et al., 2013) and four of the isolates had PFGE patterns that indicated that they were USA300 strains. ST8 MRSA has also been isolated from chickens, cows, horses, turkey, beef, and pork samples (see text footnote 2). One of the eight isolates was the only MRSA (strain 8-509) in the study to be Panton-Valentine Leukocidin (PVL) positive while the remaining MRSA were all PVL-negative in the WA samples as compared to four of eight MRSA isolates PVL+ in the Japanese study (Iwao et al., 2012).

Other ST types found in humans ST109 $(n=3)$, humans and animals ST15 $(n=2)$, ST45 $(n=4)$, ST88 $(n=1)$, ST97 $(n=4)$, or humans and meat products ST6 $(n=2)$, ST30 $(n=4)$, and ST40 $(n=4)$. ST97 is rarely found in humans and $\sim 90 \%$ of the submissions to the MLST website lists cow milk, bovine mastitis, or pigs (see text footnote 2). ST30 and ST45 belong to major clonal complexes CC30 and CC45 respectively and are often associated with human disease (Simor et al., 2002; Moore et al., 2010; Isobe et al., 2012). The MRSA ST30 clone, found in three of the WA environments, has been predominantly identified in Japanese hospitalized patients since the 1980s (Isobe et al., 2012) and have also been reported in MRSA infections from other parts of the world (Hetem et al., 2012). MRSA ST45, also found in three of the WA environments, is associated with USA600 which has been reported as an epidemic strain in Central European and Canadian hospitals (Witte et al., 1997; Simor et al., 2002) and been implicated in outbreaks of bloodstream infections in Detroit, MI, USA (Abdel-Haq et al., 2009; Moore et al., 2010).

\section{CONCLUSION}

Unlike recent studies of clinical USA300, all the environmental USA300 isolates in the current study were multi-drug resistant carrying two to six different antibiotic resistance genes. The majority
(72\%) carried four to six different antibiotic resistance genes and $\sim 95 \%$ of all the other MRSA isolates were multi-drug resistant. Similar results were found in the Japanese study of MRSA isolates from 2008 to 2010 (Iwao et al., 2012). Why there was such a high level of antibiotic resistance in environmental MRSA isolates is certainly not clear but does correlate with our previous small study (Soge et al., 2009). It is unlikely that the level of resistance found in the environmental MRSA isolates is unique to the Seattle, WA area or to the selected environmental surfaces examined. It will also be of interest to know if the environmental MRSA isolates are acquiring their antibiotic resistance genes from other members of the environmental bacterial community or if some of these genes have originated from bacteria in the hospital setting. The data suggests that the environmental MRSA isolates collected in the current study are potential antibiotic resistance gene reservoirs and should be able to act as donors to the microbes and the environmental antibiotic resistance gene pool and potentially contribute to the human microbiome antibiotic resistance gene pool.

A major difference between MRSA isolates isolated from WA recreational beaches and freshwater streams versus other WA environments is that we found no isolates related to USA300 by PFGE, though MLST type associated with USA300 and SCCmec IV were present. In contrast, in the built environments, USA300 MRSA isolates comprised $25-60 \%$ of the total number of MRSA isolates recovered (Table 1). Another major difference was that ST133 which has until recently thought to be exclusively an animal clone was one of the most commonly isolated ST type from recreational beaches $9 / 31$ (29\%) but was absent from the built environmental sites.

From all environmental sites, SCCmec IV was the most common $36 / 55$ (66\%) which is comparable with what is occurring in the health care setting with SCCmec IV replacing other SCCmec types (Healy et al., 2004; D'Agata et al., 2009). The most diversity of MLST types were found in the recreational beaches but this could be due to the larger number of different MRSA isolates included. There are a limited number of studies that have characterized environmental MRSA. The recreational beach study of Seifried et al. (2007) identified 18 USA300 isolates from recreational seawater in Hawaii. These isolates represented eight different spa types, at least three different SCCmec types and a variety of PFGE types. We did not find USA300 in our recreational samples but did find significant diversity of the MRSA strains as was found in Hawaii. Another study in California suggested that beachgoers could be a possible source of MRSA and S. aureus isolated in sand and seawater (Goodwin et al., 2012) though the isolates were not characterized to verify this hypothesis. Thus the differences we have found between MRSA strains isolated at the three recreational beaches in the Seattle and the built environmental surfaces may vary geographically with less differences between recreational beaches isolates taken from California, Hawaii or where the water is warmer and many more people swim. However it is clear that more studies characterizing the MRSA isolated in environmental setting need to be done to allow better understanding of the potential risk involved with environmental contact with MRSA and/or S. aureus contaminated community high touch surfaces and recreational beaches. 


\section{REFERENCES}

Abdel-Haq, N., Al-Tatari, H., Chearskul, P., Salimnia, H., Asmar, B., Fairfax, M., et al. (2009). Methicillinresistant Staphylococcus aureus (MRSA) in hospitalized children: correlation of molecular analysis with clinical presentation and antibiotic susceptibility testing (ABST) results. Eur. J. Clin. Microbiol. Infect. Dis. 28, 547-551.

Abdelzaher, A. M., Wright, M. E., Ortega, C., Solo-Gabriele, H. M., Miller, G., Elmir, S., et al. (2010). Presence of pathogens and indicator microbes at a non-point source subtropical recreational marine beach. Appl. Environ. Microbiol. 76, 724-732.

Bartels, M. D., Kristoffersen, K., Boye, K., and Westh, H. (2009). Rise and subsequent decline of communityassociated methicillin-resistant Staphylococcus aureus ST30-IVc in Copenhagen. Clin. Microbiol. Infect. $16,78-83$.

Börjesson, S., Matussek, A., Melin, S., Löfgren, S., and Lindgren, P. E. (2009). Methicillin-resistant Staphylococcus aureus (MRSA) in municipal wastewater: an uncharted threat? J. Appl. Microbiol. 108, 1244-1251.

Boyce, J. M., Potter-Bynoe, G., Chenevert, C., and King, T. (1997). Environmental contamination due to methicillin-resistant Staphylococcus aureus: possible infection control implications. Infect. Control Hosp. Epidemiol. 18, 622-627.

Brooke, J. S., Annand, J. W., Hammer, A., Dembkowski, K., and Shulman, S. T. (2009). Investigation of bacterial pathogens on 70 frequently used environmental surfaces in a large urban US. university. J. Environ. Health 71, 17-22.

Carmo, M. S., Inoue, F., Andrade, S. S., Paschoal, L., Silva, F. M., Olieira, V. G. S., et al. (2011). New multilocus sequence typing of MRSA in Sao Paulo. Braz. J. Med. Biolog. Res. 44, 1013-1017.

Centers for Disease Control and Prevention. (2001). Methicillinresistant Staphylococcus aureus skin or soft tissue infections in a state prison-Mississippi, 2001. MMWR Morb. Mortal. Wkly. Rep. 50, 919-922.

D’Agata, E. M.,Webb, G. F., Horn, M. A., Moellering, R. C. Jr., and Ruan, S. (2009) Modeling the invasion of community-acquired methicillinresistant Staphylococcus aureus into hospitals. Clin. Infect. Dis. 48, 274-284.
Desai, R., Pannaraj, P. S., Agopian, J., Sugar, C. A., Liu, G. Y., and Miller, L. G. (2011). Survival and transmission of communityassociated methicillin-resistant Staphylococcus aureus from fomites. Am. J. Infect Control 39, 219-225.

Eady, E. A., and Cove, J. H. (2003). Staphylococcal resistance revisited: community-acquired methicillin resistant Staphylococcus aureus-an emerging problem for the management of skin and soft tissue infections. Curr. Opin. Infect. Dis. 16, 103-124.

Elmir, S. M., Wright, M. E., Abdelzaher, A., Solo-Gabriele, H. M., Fleming, L. E., Miller, G., et al. (2007). Quantitative evaluation of bacteria released by bathers in marine water. Water Res. 41, 3-10.

Eriksson, J., Espinosa-Gongora, C., Stamphøj, I., Larsen, A. R., and Guardabassi, L. (2013). Carriage frequency, diversity and methicillin resistance of Staphylococcus aureus in Danish small ruminants. Vet. Microbiol. 163, 110-115.

Goodwin, K. D., McNay, M., Cao, Y., Ebentier, D., Madison, M., and Griffity, J. F. (2012). A multi-beach study of Staphylococcus aureus, MRSA, and enterococci in seawater and beach sand. Water Res. 46, 4195-4207.

Goodwin, K. D., and Pobuda, M. (2009). Performance of CHROMagar Staph aureus and CHROMagar MRSA for detection of Staphylococcus aureus in seawater and beach sand - comparison of culture, agglutination, and molecular analysis. Water Res. 43, 4802-4811.

Grundmann, H., Aires-de-Sousa, M., Boyce, J., and Tiemersma, E. (2006). Emergence and resurgence of methicillin-resistant Staphylococcus aureus as a public-health threat. Lancet 368, 874-885.

Healy, C. M., Hulten, K. G., Palazzi, D. L., Campbell, J. R., and Baker, C. J. (2004). Emergence of new strains of methicillin-resistant Staphylococcus aureus in a neonatal intensive care unit. Clin. Infect. Dis. 39, 1460-1466.

Hetem, D. J., Westh, H., Boye, K., Jarløv, J. O., Bonten, M. J., and Bootsma, M. C. (2012). Nosocomial transmission of community-associated methicillin-resistant Staphylococcus aureus in Danish Hospitals. J. Antimicrob. Chemother. 67, 1775-1780

Huang, R., Mehta, S., Weed, D., and Price, C. S. (2006). Methicillinresistance Staphylococcus aureus survival on hospital fomites.
Infect. Control Hosp. Epidemiol. 27, 1267-1269.

Isobe, H., Takano, T., Nishiyama, A., Hung, W. C., Kuniyuki, S., Shibuya, Y., et al. (2012). Evolution and virulence of PantonValentine leukocidin-positive ST30 methicillin-resistant Staphylococcus aureus in the past 30 years in Japan. Biomed. Res. 33, 97-109.

Iwao, Y., Yabe, S., Takano, T., Higuchi, W., Nishiyama, A., and Yamamoto, T. (2012). Isolation and molecular characterization of methicillinresistance Staphylococcus aureus from public transport. Microbiol. Immunol. 56, 76-82.

Kawaguchiya, M., Urushibara, N. Yamanoto, D., Yamsahita, T., Shinagawa, M., Watanabe, N., et al. (2013). Characterization of PVL/ACMEpositive methicillin-resistance Staphylococcus aureus (genotypes ST8-MRSA-IV and ST5-MRSA-II) isolated from a university hospital in Japan. Microb. Drug Resist. 19, 48-56.

King, M. D., Humphrey, B. J., Wang, Y. F., Kourbatova, E. V., Ray, S. M., and Blumberg, H. M. (2006). Emergence of community-acquired methicillinresistant Staphylococcus aureus USA 300 clone as the predominant cause of skin and soft-tissue infections. Ann. Intern. Med. 144, 309-317.

Klevens, R. M., Morrison, M. A., Nadle, J., Petit, S., Gersham, K., Ray, S., et al. (2007). Invasive methicillin-resistant Staphylococcus aureus infections in the United States. JAMA 298, 1763-1771.

Kluytmans, J., van Belkum, A., and Verbrugh, H. (1997). Nasal carriage of Staphylococcus aureus: epidemiology, underlying mechanism, and associated risks. Clin. Microbiol. Rev. 10, 505-520.

Larsen, J., Enright, M. C., Godoy, D. Spratt, B. G., Larsen, A. R., and Skov, R. L. (2012). Multilocus sequence typing scheme for Staphylococcus aureus: revision of the gmk locus. J. Clin. Microbiol. 50, 2538-2539.

Levin-Edens, E., Soge, O. O., No, D. B., Stiffarm, A., Meschke, J. S., and Roberts, M. C. (2012). Methicillinresistant Staphylococcus aureus from Northwest marine and fresh water recreational beaches. FEMS Microbiol. Ecol. 79, 412-420.

McDougal, L. K., Fosheim, G. E., Nicholson, A., Bulens, S. N., Limbago, B. M., Shearer, J. E. S., et al. (2010). Emergence of resistance among USA300 methicillinresistant Staphylococcus aureus isolates causing invasive disease in the Unite States. Antimicrob. Agents Chemother 54, 3804-3811.

Meemken, D., Blaha, T., Hotzel, H., Strommenger, B., Klein, G., Ehricht, R., et al. (2013). Genotypic and phenotypic characterization of Staphylococcus aureus from wild boars. Appl. Environ. Microbiol. 79, 1739-1742.

Moore, C. L., Osaki-Kiyan, P., Perri, M., Donabedian, S., Haque, N. Z., Chen, A., et al. (2010). USA600 (ST45) methicillin-resistant Staphylococcus aureus bloodstream infections in urban Detroit. J. Clin. Microbiol. 48, 2307-2310.

Nguyen, D. M., Mascola, L., and Brancoft, E. (2005). Recurring methicillin-resistant Staphylococcus aureus infections in a football team. Emerg. Infect. Dis. 11, 526-532.

Nimmo, G. R., and Coombs, G. W. (2008). Community-associated methicillin-resistant Staphylococcus aureus (MRSA) in Australia. Int. J. Antimicob. Agents 31, 401-410.

Otter, J. A., and French, G. L. (2009). Bacterial contamination on touch surfaces in the public transport system and in public areas of a hospital in London. Lett. App. Microbiol. 49, 803-805.

Otter, J. A., Yezli, S., and French, G. L. (2011). The role played by contaminated surfaces in the transmission of nosocomial pathogens. Infect. Control Hosp. Epidemiol. 32, 687-699.

Plano, L. R. W., Garza, A. C., Shibata, T., Elmir, S. M., Kish, J., Sinigalliano, C. D., et al. (2011). Shedding of Staphylococcus aureus and methicillin-resistant Staphylococcus aureus from adult and pediatric bathers in marine waters. $B M C$ Microbiol. 11:5. doi:10.1186/14712180-11-5

Popovich, K. J., Weinstein, R. A., and Hota, B. (2008). Are communityassociated methicillin-resistant Staphylococcus aureus (MRSA) strains replacing traditional nosocomial MRSA strains? Clin. Infect. Dis. 46, 787-794.

Roberts, M. C., Soge, O. O., Horst, J. A., Ly, K. A., and Milgrom, P. (2011a). MRSA from dental school surfaces and students. Am. J. Infect. Control. 39, 628-632.

Roberts, M. C., Soge, O. O., No, D. B., Beck, N., and Meschke, J. S. (2011b). Isolation and characterization of methicillin-resistant Staphylococcus aureus (MRSA) from fire stations in two Northwest fire districts. Am. J. Infect. Control 39, 382-389.

Roberts, M. C., Soge, O. O., No, D. B., Helgeson, S. E., and Meschke, 
J. S. (2011c). Characterization of methicillin-resistant Staphylococcus aureus isolated from public surfaces on a University campus, student homes and local community. J. Appl. Microbiol. 110, 1531-1537.

Sasaki, T., Tsubakishita, S., Tanaka, Y., Ohtsuka, M., Hongo, I., Fukata, T., et al. (2012). Population genetic structures of Staphylococcus aureus isolates from cats and dogs in Japan. J. Clin. Microbiol. 50, 2152-2155.

Schwalm, N. D. III., Verghese, B., and Knabel, S. J. (2011). A novel multiplex PCR method for detecting the major clonal complexes of MRSA in nasal isolates form a Pennsylvania hospital. J. Microbiol. Methods 86, 379-382.

Scott, E., Duty, S., and McCue, K. (2009). A critical evaluation of methicillinresistant Staphylococcus aureus and other bacteria of medical interest on commonly touched household surfaces in relation to household demographics. Am. J. Infect. Control. 37, 447-453.

Seifried, S. E., Tice, A. D., and Eischen, M. (2007). Diversity of community-associated strains of methicillin-resistant Staphylococcus aureus in Hawaii. J. Infect. Dis. 195, 305.

Selvakumar, A., and Borst, M. (2006). Variation of microorganism concentration sin urban stormwater runoff with land use and seasons. J. Water Health 4, 109-124.

Simor, A. E., Ofner-Agostini, M., Bryce, E., McGeer, A., Paton, S., and Mulvey, M. R. (2002). Laboratory characterization of methicillinresistant Staphylococcus aureus in Canadian hospitals: results of 5 years of national surveillance, 1995-1999. J. Infect. Dis. 186, 652-660.

Smyth, D. S., Feil, E. J., Meaney, W. J., Hartigan, P. J., Tollersrud, T., Fitzgerald, J. R., et al. (2009). Molecular genetic typing reveals further insights into the diversity of animal-associated Staphylococcus aureus. J. Med. Microbiol. 58, 1343-1353.

Soge, O. O., Meschke, J. S., No, D. B., and Roberts, M. C. (2009). Characterization of methicillinresistant Staphylococcus aureus (MRSA) and methicillin-resistant coagulase-negative Staphylococcus spp. (MRCoNS) isolated from West Coast public marine beaches. J. Antimicrob. Chemother. 64, 1148-1155.

Tenover, F. C., McDougal, L. K., Goering, R. V., Killgove, G., Porhan, S. J., Patel, J. B., and Dunmann, P. M. (2006). Characterization of a strain of community-associated Methicillin-resistant Staphylococcus aureus widely disseminated in the United States. J. Clin. Microbiol. 44, 108-118.
Tenover, F. C., and Goering, R. V. (2009). Methicillin-resistant Staphylococcus aureus strain USA300: origin and epidemiology. J. Antimicrob. Chemother. 64 441-446.

Tice, A. D., Pombo, D., Hui, J., Kurano, M., Bankowski, M. J., and Seifried, S. E. (2010). Quantification of Staphylococcus aureus in seawater using CHROMagar SA. Hawaii Med. J. 69, 8-12.

Verghese, B., Schwalm, N. D. III., Gudley, E. G., and Knabel, S. J. (2012). A combined multi-virulence-locus sequence typing and Staphylococcal cassette chromosome mec typing scheme possesses enhanced discriminatory power for genotyping MRSA. Infect. Genet. Evol. 12, 1816-1821.

Viau, E. J., Goodwin, K. D., Yamahara, K. M., Layton, B. A., Sassoubre, L. M., Burns, S. L., et al. (2011) Bacterial pathogens in Hawaiian coastal streams - associations with fecal indicators, land cover and water quality. Water Res. 45, 3279-3290.

Witte, W., Kresken, M., Braulke, C., and Cuny, C. (1997). Increasing incidence and widespread dissemination of methicillin-resistant Staphylococcus aureus (MRSA) in hospitals in central Europe, with special reference to German hospitals. Clin. Microbiol. Infect. 3, 414-422.
Zuckerman, J. B., Zuaro, D. E., Prato, B. S., Ruoff, K. L., Sawicki, R. W., Quinton, H. B., et al. (2009). Bacterial contamination of cystic fibrosis clinics. J. Cystic Fibros 8, 186-192.

Conflict of Interest Statement: The authors declare that the research was conducted in the absence of any commercial or financial relationships that could be construed as a potential conflict of interest.

Received: 17 January 2013; paperpending published: 19 February 2013; accepted: 14 March 2013; published online: 04 April 2013.

Citation: Roberts MC, Soge OO and No $D$ (2013) Comparison of multidrug resistant environmental methicillinresistant Staphylococcus aureus isolated from recreational beaches and high touch surfaces in built environments. Front. Microbiol. 4:74. doi: 10.3389/fmicb.2013.00074

This article was submitted to Frontiers in Antimicrobials, Resistance and Chemotherapy, a specialty of Frontiers in Microbiology.

Copyright ( $\odot 2013$ Roberts, Soge and No. This is an open-access article distributed under the terms of the Creative Commons Attribution License, which permits use, distribution and reproduction in other forums, provided the original authors and source are credited and subject to any copyright notices concerning any third-party graphics etc. 